\title{
Fat classes of welded steel details derived from the master design curve of the peak stress method
}

\author{
Michele Zanetti ${ }^{1,2} \cdot$ Vittorio Babini ${ }^{2} \cdot$ Giovanni Meneghetti ${ }^{1}$ \\ Received: 12 October 2019 / Accepted: 23 December 2020 \\ (C) The Author(s) 2021, corrected publication 2021
}

\begin{abstract}
In this paper, the peak stress method (PSM) is adopted to analyse the fatigue strength of steel welded joints. According to this method, a single design curve is expressed in terms of a properly defined equivalent peak stress and it is valid for fatigue design of arc-welded steel joints. Private companies often need simple finite element beam models for fatigue strength assessments, because of the large dimensions of the structures. However, beam elements provide nominal stresses (and not local stresses) that must be compared with appropriate fatigue strength values (the FAT classes) available in design standards. Due to the limited number of FAT classes available, finding the appropriate one is frequently troublesome, particularly when complex geometries are considered. The objective of this work is to define FAT classes in terms of nominal stress for a number of geometrically complex structural details, starting from the design curve of the PSM. FAT classes have also been determined using the hot spot stress approach. Then the results obtained with the two methods are compared. The structural details analysed in the present paper are typically adopted in amusement park structures and are not classified in common design standards.
\end{abstract}

Keywords Peak Stress Method (PSM) · Fatigue design $\cdot$ Local approaches $\cdot$ FE analysis $\cdot$ Coarse mesh $\cdot$ Hot spot stress

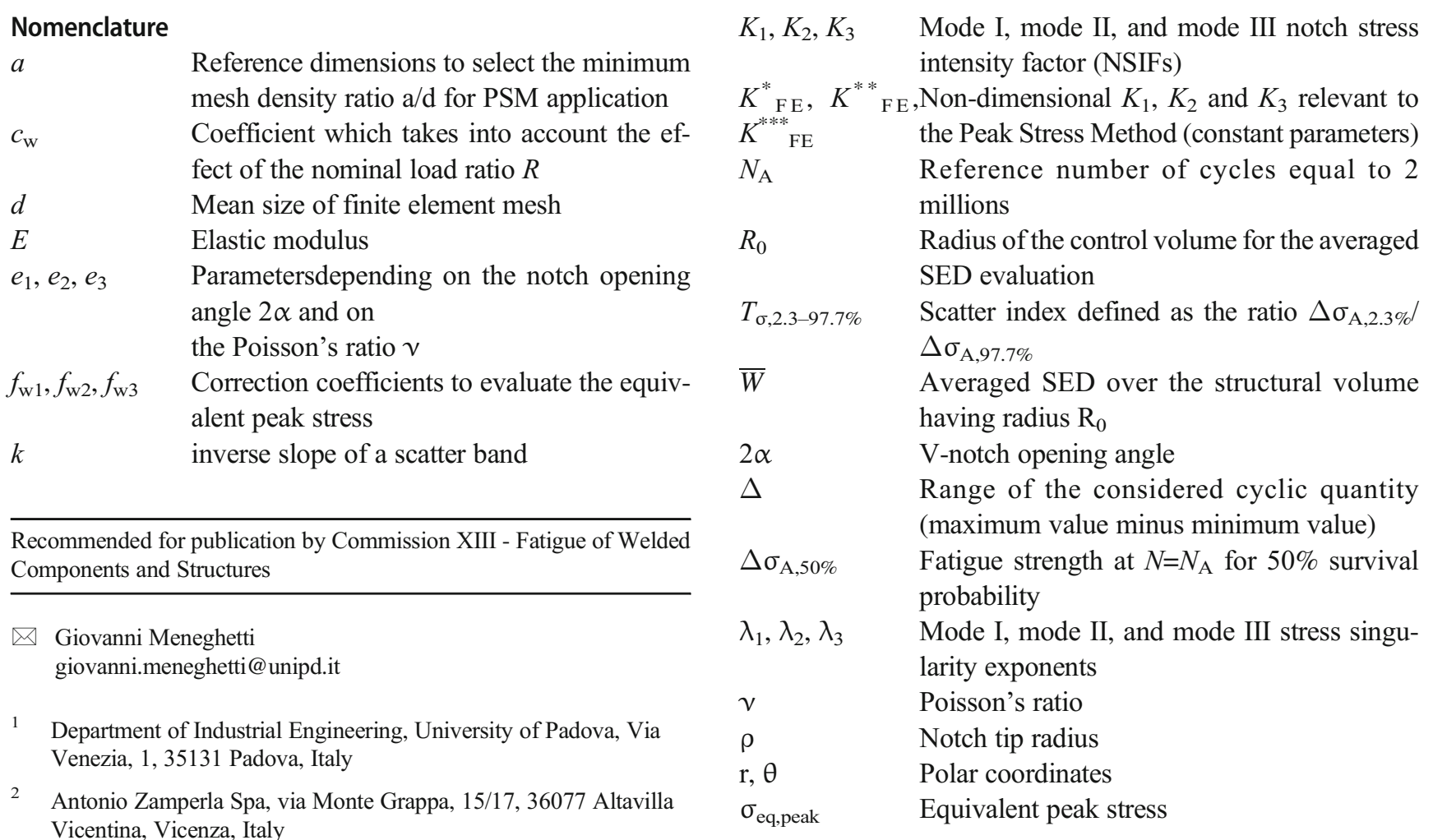




\begin{tabular}{|c|c|}
\hline$\sigma_{\mathrm{HS}}$ & Hot spot stress \\
\hline$\sigma_{\text {nom }}$ & Applied nominal stress \\
\hline$\sigma_{\theta \theta}, \tau_{\mathrm{r} \theta}, \tau_{\theta \mathrm{z}}$ & $\begin{array}{l}\text { Normal and shear stress components in the } \\
\text { polar frame of reference }\end{array}$ \\
\hline$\sigma_{\theta \theta, \theta=0, \text { peak }}$ & $\begin{array}{l}\text { Singular, linear elastic, opening (mode I) } \\
\text { peak stress evaluated by FEM at a sharp V- } \\
\text { notch tip }\end{array}$ \\
\hline$\tau_{\mathrm{r} \theta, \theta=0, \text { peak }}$ & $\begin{array}{l}\text { Singular, linear elastic, in-plane shear (mode } \\
\text { II) peak stress evaluated by FEM at a sharp } \\
\text { V-notch tip }\end{array}$ \\
\hline$\tau_{\theta z, \theta=0, \text { peak }}$ & $\begin{array}{l}\text { Singular, linear elastic, anti-plane shear } \\
\text { (mode III) peak stress evaluated by FEM at } \\
\text { a sharp V-notch tip }\end{array}$ \\
\hline
\end{tabular}

Abbreviations

FE Finite element

FEM Finite element method

FAT Fatigue strength class

PSM Peak Stress Method

SED Strain energy density

NSIF Notch stress intensity factor

\section{Introduction}

Different design approaches are available in design standards and recommendations in order to assess the fatigue strength of welded joints. They include the nominal stress, the hot spot stress, the fictitious notch rounding and the linear elastic fracture mechanics (LEFM) approaches $[1,2]$. The nominal stress approach is simple to apply in that stresses are calculated from the beam theory. However, detail categories, i.e. FAT classes, must be available for each geometry of the joint. Design standards and recommendations collect several categories and provide the nominal stress-based design curve, along with the correction factors to account for thickness and/or shape effects, if applicable. In this context, local approaches adopt local stresses to design against fatigue, in order to includethe effects of welded joint geometry (shape effect) as well as absolute dimensions (scale effect) in the stress analysis.

Notch-stress intensity factors (N-SIFs) proved to be effective, linear elastic, local stress parameters for fatigue design of welded joints [3, 4]. Subsequently, a FE-based method, called Peak Stress Method (PSM), has been proposed to calculate rapidly the NSIFs with $2 \mathrm{D}$ or $3 \mathrm{D}$ FE analyses using a coarse mesh [5].

Even though the NSIF-based local approaches proved to be effective and robust, nevertheless private companies often need simple finite element beam models for fatigue strength assessments, owing to the large dimensions of the structures, which makes it difficult to use shell or three-dimensional FE models. Therefore, the nominal stress approach based on FAT classes is adopted. However, finding appropriate FAT classes consistent with the analysed welded joint geometry is frequently troublesome, particularly when complex geometries are treated.

The main objective of this work is to define new FAT classes in terms of nominal stress for a number of geometrically complex welded structural details in structural steel, starting from the master design curve previously defined according to the PSM. Structural details analysed here are typically adopted in amusement park structures and in several cases they are not classified in design standards for steel structures. Even though a three-dimensional FE analysis must be performed to apply the PSM, the numerical effort is worth the result obtained, if we consider, on the other side, the experimental effort that would be required to perform full-scale fatigue tests on geometrically complex welded structures. Moreover, the three-dimensional analysis requires a relatively coarse mesh, as detailed in a next section of this paper. For comparison purposes, FAT classes are derived also by using the hot spot stress approach, when applicable (for example the hot spot stress approach is not suitable to assess weld root fatigue). Eventually, a comparison with FAT classes available in design standards is also reported.

The content of this paper can be summarised as follows: (i) a short summary of the two methods used (PSM and hot spot method) from a theoretical point of view, (ii) description of the procedure adopted to determine FAT classes, (iii) discussion of results and (iv) presentation of a case study consisting of a lattice-type complex structure, where the Peak Stress Method has been applied directly by using three-dimensional FE models.

\section{Theoretical background}

\subsection{Peak Stress Method}

The Peak Stress Method (PSM) is an engineering, FEoriented application of the notch stress intensity factor (NSIF) approach to fatigue design of welded joints, which assumes both the weld toe and the weld root as sharp $\mathrm{V}$-notches, having a notch tip radius $\rho=0$ and a notch opening angle $2 \alpha \geq 0^{\circ}$ (typically $135^{\circ}$ for the weld toe and $0^{\circ}$ for the weld root). Under these assumptions, the local, linear elastic stress fields in the vicinity of the notch tip depends on the relevant NSIFs, which quantify the magnitude of the asymptotic singular stress distribution. For a thorough discussion on the NSIF approach, see [3, 4]. However, applying the NSIF approach requires extremely fine FE meshes at the notch tip (element size on the order of $10^{-5} \mathrm{~mm}$ ) and therefore requires long time for mesh generation, model solution and analysis of results. Consequently, this approach can hardly be applied in the industry to solve structural engineering problems. 
Fig. 1 Typical pipe-flange welded joint under multiaxial fatigue loading with the respective linear elastic peak stress components at the weld toe and the weld root

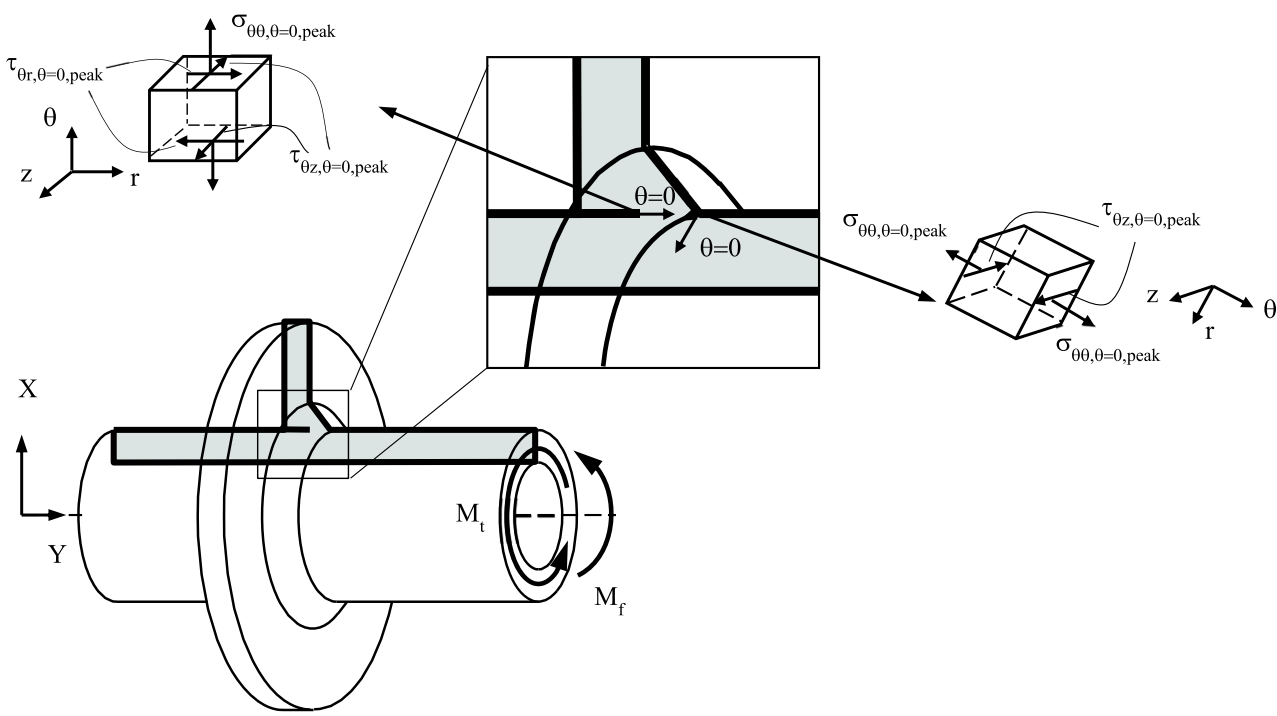

To attack this problem, the Peak Stress Method (PSM) has been proposed [5], see Fig. 1, in order to readily estimate the NSIFs $\mathrm{K}_{1}, \mathrm{~K}_{2}$ and $\mathrm{K}_{3}$ starting from the singular, linear elastic, opening (mode I), sliding (mode II) and tearing (mode III) peak stresses $\sigma_{\theta \theta}, \theta=0$, peak $, \tau_{r \theta}, \theta=0$, peak and $\tau_{\theta z}, \theta=0$, peak, respectively. The peak stresses are calculated at the notch tip from FE analyses with coarse meshes, if compared to the very refined mesh required to evaluate the NSIFs. The polar frame of reference $(r, \theta)$ is referred to the $\mathrm{V}$-notch bisector line, as depicted in Fig. 1. The estimated NSIFs values can be obtained from the following expressions [5-7]:

$K_{1}=K_{\mathrm{FE}}^{*} \cdot \sigma_{\theta \theta, \theta=0, \text { peak }} \cdot \mathrm{d}^{1-\lambda_{1}}$

$K_{2}=K_{\mathrm{FE}}^{* *} \cdot \tau_{\mathrm{r} \theta, \theta=0, \text { peak }} \cdot \mathrm{d}^{1-\lambda_{2}}$

$K_{3}=K_{\mathrm{FE}}^{* * *} \cdot \tau_{\theta z, \theta=0, \text { peak }} \cdot \mathrm{d}^{1-\lambda_{3}}$

where $d$ is the ' $g l o b a l$ element size', i.e. the average FE size adopted by free mesh generation algorithm available in $\mathrm{FE}$ software; parameters $\lambda_{i}$ are the mode I, II and III eigenvalues which are dependent on the notch opening angle $2 \alpha$; parameters $K_{\mathrm{FE}}^{*}, K_{\mathrm{FE}}^{* *}$ and $K_{\mathrm{FE}}^{* * * *}$ depend on the calibration options: (i) element type and formulation, (ii) mesh pattern and (iii) procedure for stress extrapolation at FE nodes.

Originally, the PSM has been calibrated by using 2D fournode plane elements available in Ansys ${ }^{\circledR}$ library and the outcome has been as follows: (i) $K_{\mathrm{FE}}^{*}=1.38$, (ii) $K_{\mathrm{FE}}^{* *}=3.38$ and (iii) $K_{\mathrm{FE}}^{* * *}=1.93$ under conditions reported in [5-7], to which the reader is referred. Afterwards, the PSM has been extended to eight-node 3D brick elements [8] obtained from mesh extrusion, taking advantage of submodeling technique available in Ansys ${ }^{\circledR}$. Furthermore, to broaden the applicability of the PSM, parameters $K_{\mathrm{FE}}^{*}$ and $K_{\mathrm{FE}}^{* *}$ have been also calibrated for six commercial FE packages other than Ansys ${ }^{\circledR}[9]$.

Since the units of NSIFs depend on the notch opening angle $2 \alpha$, fatigue assessments of weld roots and toes cannot be performed by a direct comparison of NSIF values. This problem was overcome by the approach based on the range of the total elastic strain energy (SED) averaged over a sector of radius $R_{0}$ surrounding the weld toe and the weld root. For a complete discussion of the method, see [10-14].

Considering a general multiaxial load condition (mixed mode I, II and III), by using the PSM relationships (Eqs. (1)-(3)), the closed-form expression of averaged SED re-converted to an equivalent uniaxial stress can be rewritten as function of the singular, linear elastic FE peak stresses as follows $[15,16]$ :

$\Delta \sigma_{\text {eq,peak }}=\sqrt{c_{w 1} \cdot f_{w 1}^{2} \cdot \Delta \sigma_{\theta \theta, \theta=0, \text { peak }}^{2}+c_{w 2} \cdot f_{w 2}^{2} \cdot \Delta \tau_{r \theta, \theta=0, p e a k}^{2}+c_{w 3} \cdot f_{w 3}^{2} \cdot \Delta \tau_{\theta z, \theta=0, \text { peak }}^{2}}$

where $f_{w i}(i=1,2,3)$ are known parameters, which have been defined in detail in [5-7] and coefficients $c_{\mathrm{wi}}(i=1,2,3)$ are known correction factors, which are to be used only in case of stress relieved joints and depend on the applied stress ratio [12].
The scatter band reported in Fig. 2 is expressed in terms of range of the equivalent peak stress (Eq. (4)) and it has been originally calibrated by using approximately 180 well documented experimental results taken from the literature, which 
Fig. 2 Resistance curves of the PSM in terms of equivalent peak stress validated by using approximately 1000 experimental data relevant to weld root and weld toe failures in arc-welded joints loaded under mode I+II [15, 16]

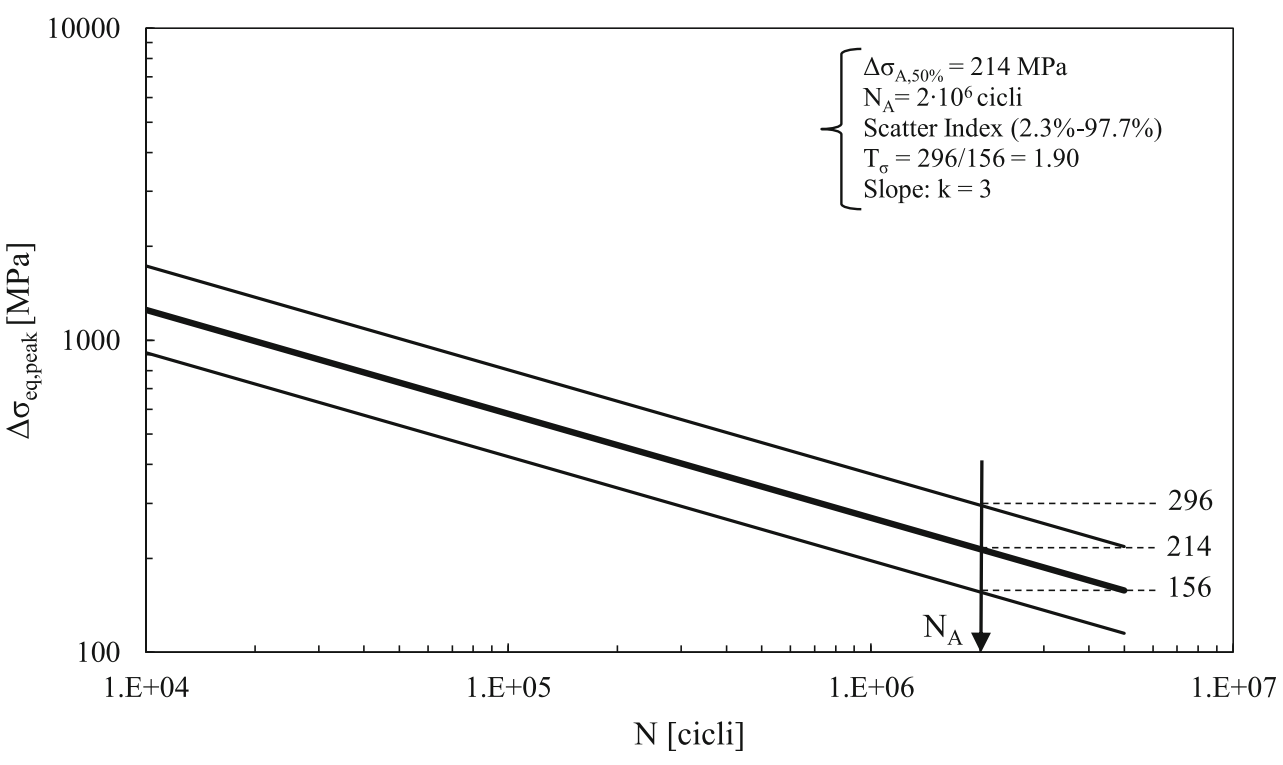

had been generated by testing fillet- or full-penetration, T- or cruciform welded joints in the as-welded condition and made of structural steel. Subsequently, the design scatter band reported in Fig. 2 has been successfully validated by using approximately 1000 experimental results relevant to weld toe and weld root failures for arc-welded steel joints, in aswelded conditions and subjected to multiaxial loads $[15,16]$.

$3 \mathrm{D}$ modelling of large-scale structures is increasingly adopted in industrial applications, thanks to the growing spread of high-performance computing (HPC) resources. Owing to this trend, the PSM has been recently calibrated also for 10-nodes tetra elements (SOLID 187 in Ansys ${ }^{\circledR)}$ ) [17]. Meshing with tetra element proved to be efficient for large and complex 3D structures, making the PSM applicable to a single FE model, provided that adequate computing resources are available. Therefore, submodelling is no longer necessary.

When adopting tetrahedral elements, the mesh pattern resulting from the free mesh generation algorithm is characterised by the following features with reference to the line representing the $\mathrm{V}$-notch tip:

Table 1 Summary ofcalibrated $K_{\mathrm{FE}}^{*}, K_{\mathrm{FE}}^{* *}$ and $K_{\mathrm{FE}}^{* * *}$ for 10 -node tetrahedral elements (SOLID 187 of Ansys ${ }^{\circledR}$ )

\begin{tabular}{lllll}
\hline & & \multicolumn{2}{l}{ Limitations of applicability } \\
\cline { 3 - 5 } & & & $2 \alpha$ & $a / d$ \\
\hline Mode I & $K_{\mathrm{FE}}^{*}$ & $1.01 \pm 15 \%$ & $0^{\circ}, 90^{\circ}$ & $\geq 3$ \\
& & $1.21 \pm 10 \%$ & $135^{\circ}$ & $\geq 1$ \\
Mode II & $K_{\mathrm{FE}}^{* *}$ & $1.63 \pm 20 \%$ & $0^{\circ}$ & $\geq 1$ \\
Mode III & $K_{\mathrm{FE}}^{* * *}$ & $1.37 \pm 10 \%$ & $0^{\circ}$ & $\geq 2$ \\
& & $1.75 \pm 5 \%$ & $135^{\circ}$ & $\geq 2$ \\
\hline
\end{tabular}

- The shape of the finite elements having a node located at the V-notch tip is not uniform.

- The number of elements sharing a node located at the Vnotch tip is not constant for all nodes.

The previous two features add a source of inaccuracy to the 3D PSM in estimating the NSIFs, as compared to the original 2D PSM. An evident effect of such additional inaccuracy has been highlighted in case of 3D geometries subjected to particular constraints, which imply a constant NSIF distribution along the line representing the V-notch tip: by contrast, the distribution of the peak stress was found to vary within a certain scatter band [17]. In order to reduce this scatter, an average peak stress value has been proposed, by applying a moving average over three adjacent vertex nodes. Alternatively stated, the average peak stress at node $n=k$ is defined as:

$\bar{\sigma}_{i j, p e a k, n=k}=\left.\frac{\sigma_{i j, p e a k, n=k-1}+\sigma_{i j, p e a k, n=k}+\sigma_{i j, p e a k, n=k+1}}{3}\right|_{n=\text { node }}$

Table 1 reports constants $K_{\mathrm{FE}}^{*}, K_{\mathrm{FE}}^{* *}$ and $K_{\mathrm{FE}}^{* * *}$ calibrated for ten-node tetra elements [17] and the relevant conditions of applicability for different notch opening angles $(2 \alpha)$.

\subsection{Hot Spot stress approach}

The hot spot stress approach is a widely used method to assess the fatigue strength, which considers structural stress concentration factors at a welded discontinuity to be used in combination with a unified S-N curve, having slope $m=3$ and two possible endurable stresses: FAT 90 or FAT 100, depending on detail category [2]. The structural stress at the hot spot 
Fig. 3 Definition of hot spot stress

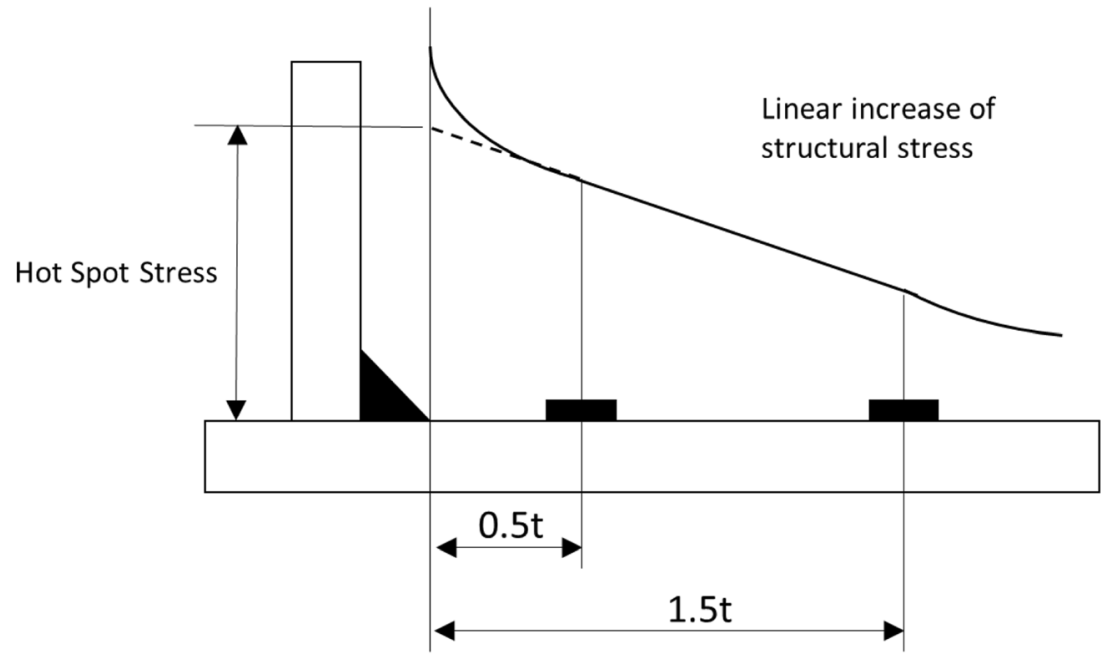

Table 2 Analysed geometries (dimensions in [mm])

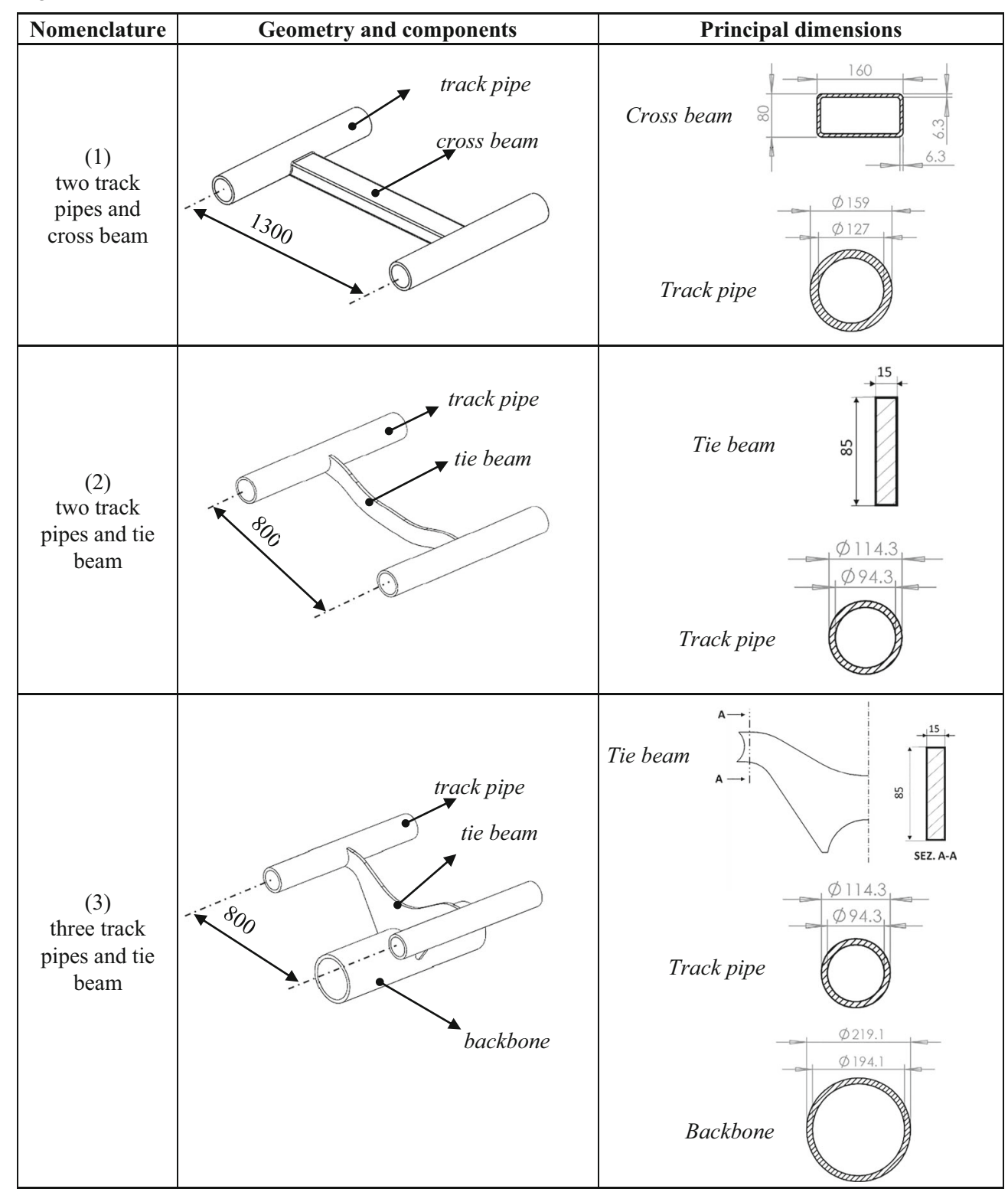


includes all stress raising effects of a structural detail, excluding the local stress peak due to the local weld profile.

To determine the hot spot stress at the weld toe a linear extrapolationbased on two points is to be carried out as shown in Fig. 3. According to the type A hot spot approach reported in IIW Recommendations [2], extrapolation points are located at $0.5 t$ and $1.5 t$, where $t$ is the plate thickness.

\section{Fat classes for unclassified welded joint geometries}

As mentioned before, welded structural details in structural steel are considered in this paper, which are typically adopted in amusement park structures. Table 2 presents the analysed geometries with their main dimensions.

For each geometry, FAT classes in terms of applied nominal stress have been defined by using two approaches:

- starting from the design curve of the PSM $[15,16]$, as described in Section 3.1;

- starting from the design curve defined in terms of hot spot stress [2], as described in Section 3.2.
FAT classes have been defined for each elementary loading condition acting on the welded joint, i.e. by axial stress or inplane as opposed to out-of-plane bending moment acting on the track pipe or on the cross beam/tie beam. Table 3 shows in detail the loading conditions and the relevant nomenclature adopted.

For each geometry, (i) full-penetration welds as well as (ii) fillet welds have been considered in order to assess the fatigue criticality of the weld root as compared to the weld toe, whenever possible.

\subsection{Definition of FAT classes by using the Peak Stress Method}

The general approach applied to determine FAT classes is summarised in following points.

- 3D modelling and meshing with 10-node tetra elements (SOLID 187) by setting a global element size in compliance with the conditions of applicability of the PSM reported in Table 1.

- Evaluation of the three linear elastic peak stresses $\left(\sigma_{\theta \theta, \theta=0, \text { peak }}, \tau_{\mathrm{r} \theta, \theta=0, \text { peak }}\right.$ and $\left.\tau_{\theta z, \theta=0, \text { peak }}\right)$ along three

Table 3 Elementary loading conditions acting on the welded connections

\begin{tabular}{|c|c|c|}
\hline \multicolumn{3}{|c|}{$\begin{array}{l}\text { Loads condition acting on track pipe } \\
\text { Valid for geometries (1), (2) and (3) }\end{array}$} \\
\hline $\begin{array}{l}\text { axial load } \\
\text { track pipe }\end{array}$ & $\begin{array}{l}\text { in plane } \\
\text { bending } \\
\text { track pipe }\end{array}$ & $\begin{array}{l}\text { out of plane } \\
\text { bending } \\
\text { track pipe }\end{array}$ \\
\hline axP & ipbP & opbP \\
\hline$F_{x}$ & $M_{y}$ & $M_{z}$ \\
\hline$\stackrel{x}{\rightarrow}$ & $\mathcal{L}$ & $\stackrel{\leftrightarrow}{Z}_{\mathrm{Z}}^{\mathrm{x}}$ \\
\hline
\end{tabular}

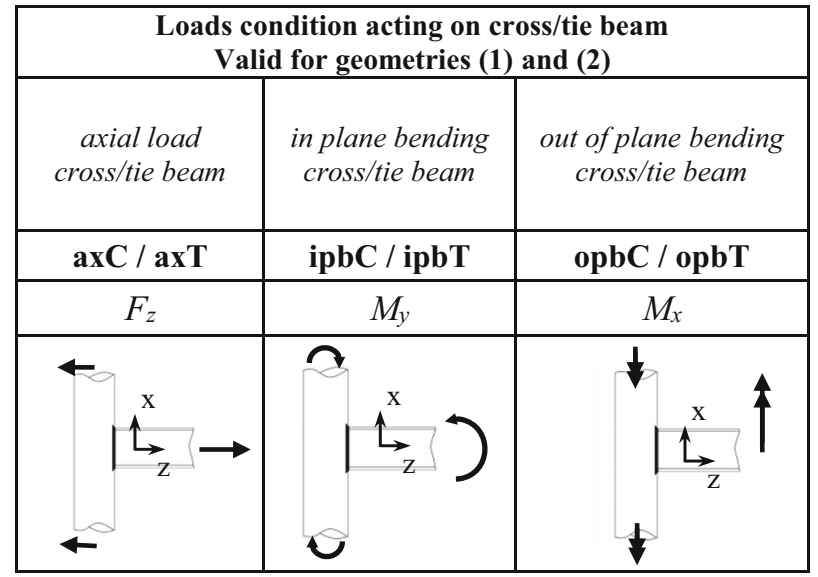

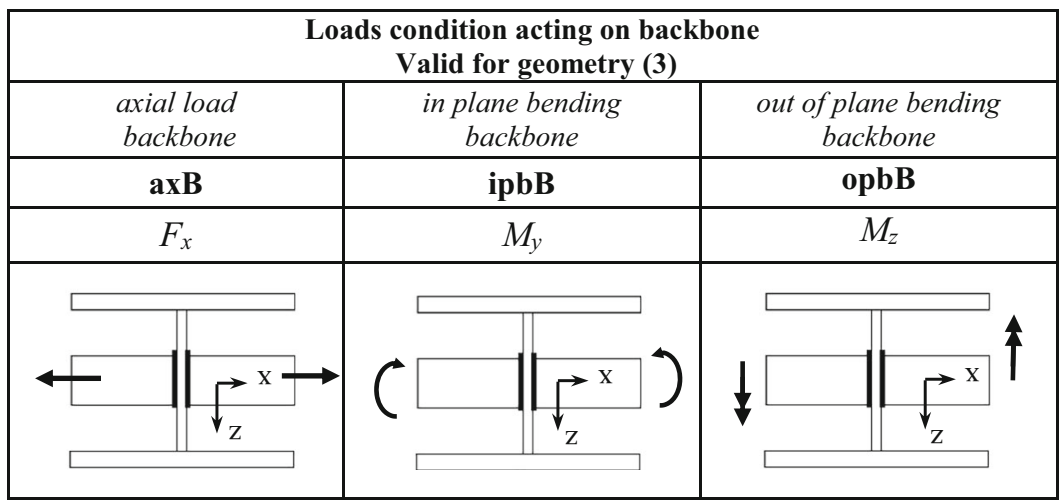


Fig. 4 Paths used forevaluating the linear elastic peak stresses (the exampleis relevant to twotrack pipes with cross beam)

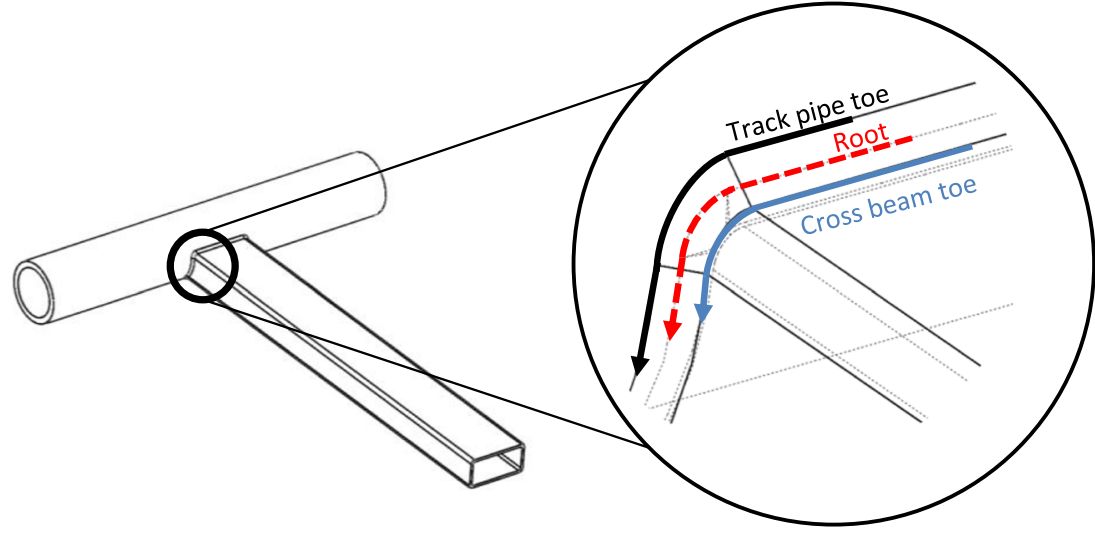

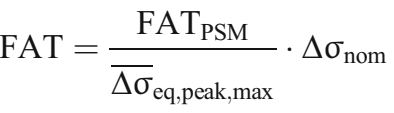
i.e. the weld toe of the track pipe, the weld toe of the cross/tie beam and the weld root if applicable. The average value at each node has been calculated by means of Eq. (5) and after that the three components are combined in order to obtain the equivalent peak stress.

- The maximum value of the average equivalent peak stress is used to define the fatigue strength class (FAT) with the following expression: where:

- $\Delta \sigma_{\text {nom }}$ is the nominal stress referred to loaded component and calculated with the known formulas: $\frac{\mathrm{F}}{\mathrm{A}}$ for axial force and $\frac{\mathrm{M}}{\mathrm{W}_{\mathrm{f}}}$ for bending, where area (A) and section modulus

Table 4 Example of the method used to calculate FAT classes adopting the PSM

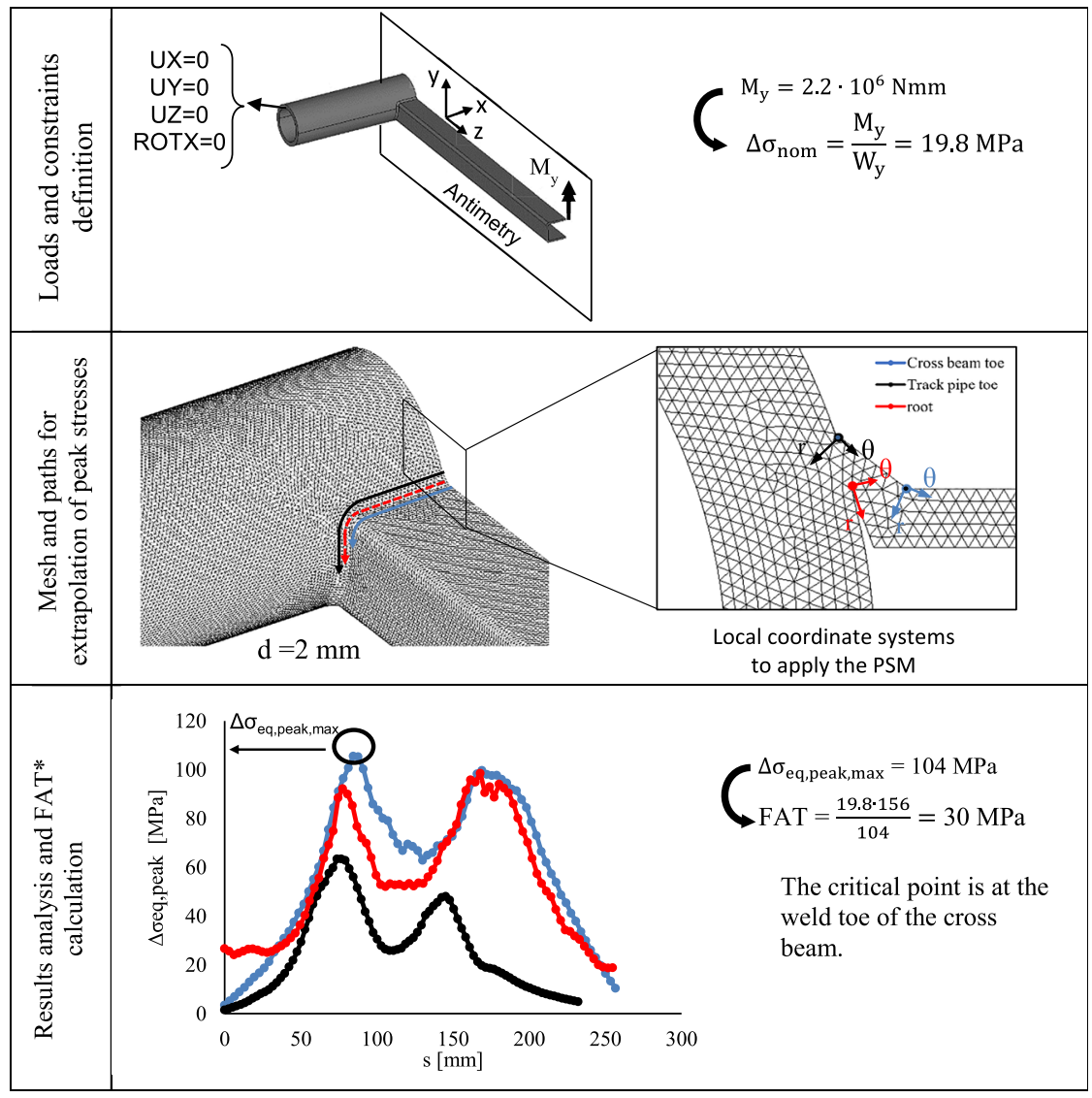


Table 5 Example of the method used to calculate FAT classes adopting the hot spot stress approach

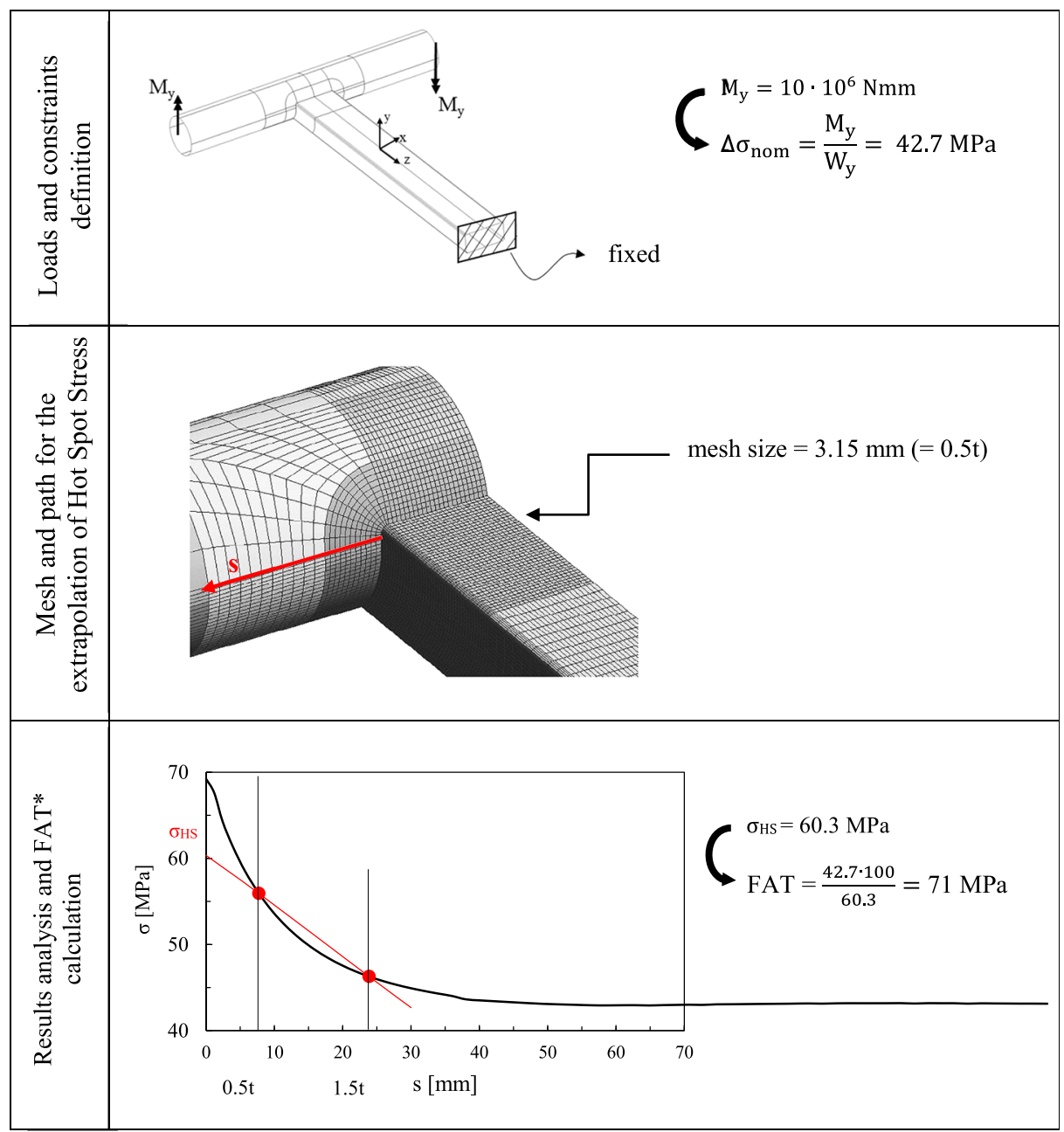

$\left(W_{\mathrm{f}}\right)$ are referred to net cross-section of the component (see Table 2).

- FAT $_{\mathrm{PSM}}$ is the fatigue class at 2 million cycles and survival probability of $97.7 \%$ valid for the equivalent peak stress-based fatigue curve; Fig. 2 shows that FAT $_{\mathrm{PSM}}=$ $156 \mathrm{MPa}[15,16]$.

Table 4 reports an example of the procedure described above applied to determine the FAT value by using the PSM. The example reported refers to following conditions:

- geometry: 2 track pipes with cross beam (Table 2)

- weld type: fillet weld

- loading condition: in plane bending of the cross beam (ipbC-Table 3)

All loading conditions shown in Table 3 have been applied to each geometry shown in Table 2 , following the procedure described in Table 4.

\subsection{Definition of FAT classes by using the hot spot method}

FAT classes have also been determined by using the hot spot stress approach, according to the type A hot spot reported in IIW Recommendations [2]. It should be recalled that the hot spot stress approach cannot be applied to assess weld root fatigue.

The procedure adopted is similar to that used for the PSM, but structural stresses are considered here and not local stresses, according to the following steps:

- Definition of the FE model using shell elements. In these analyses, the weld has not been modelled; therefore, its extra stiffness is potentially missing in the model. However, this circumstance is covered by IIW recommendations [2], as explained in the next step. A regular and sufficiently fine mesh (with an element size at least equal to $0.5 \mathrm{t}$ ) is required near the intersection of two components in order to capture hot spot stresses, using quadratic elements. 
- Linear extrapolation of the hot spot stress $\left(\sigma_{\mathrm{HS}}\right)$ as described in Section 2.2. In all cases, the maximum principal stress has been used. Note that the hot spot evaluation point is located at the intersection between the two intersecting surfaces of the shell element model. This procedure is recommended when the weld is not modelled to avoid stress underestimation due to the missing stiffness of the weld [2].
- The detected hot spot stress is used to define the FAT class with the following expression:

$\mathrm{FAT}=\frac{\mathrm{FAT}_{\mathrm{HS}}}{\Delta \sigma_{\mathrm{HS}}} \cdot \Delta \sigma_{\mathrm{nom}}$

where:

Table 6 FAT values for the analysed geometries and load conditions

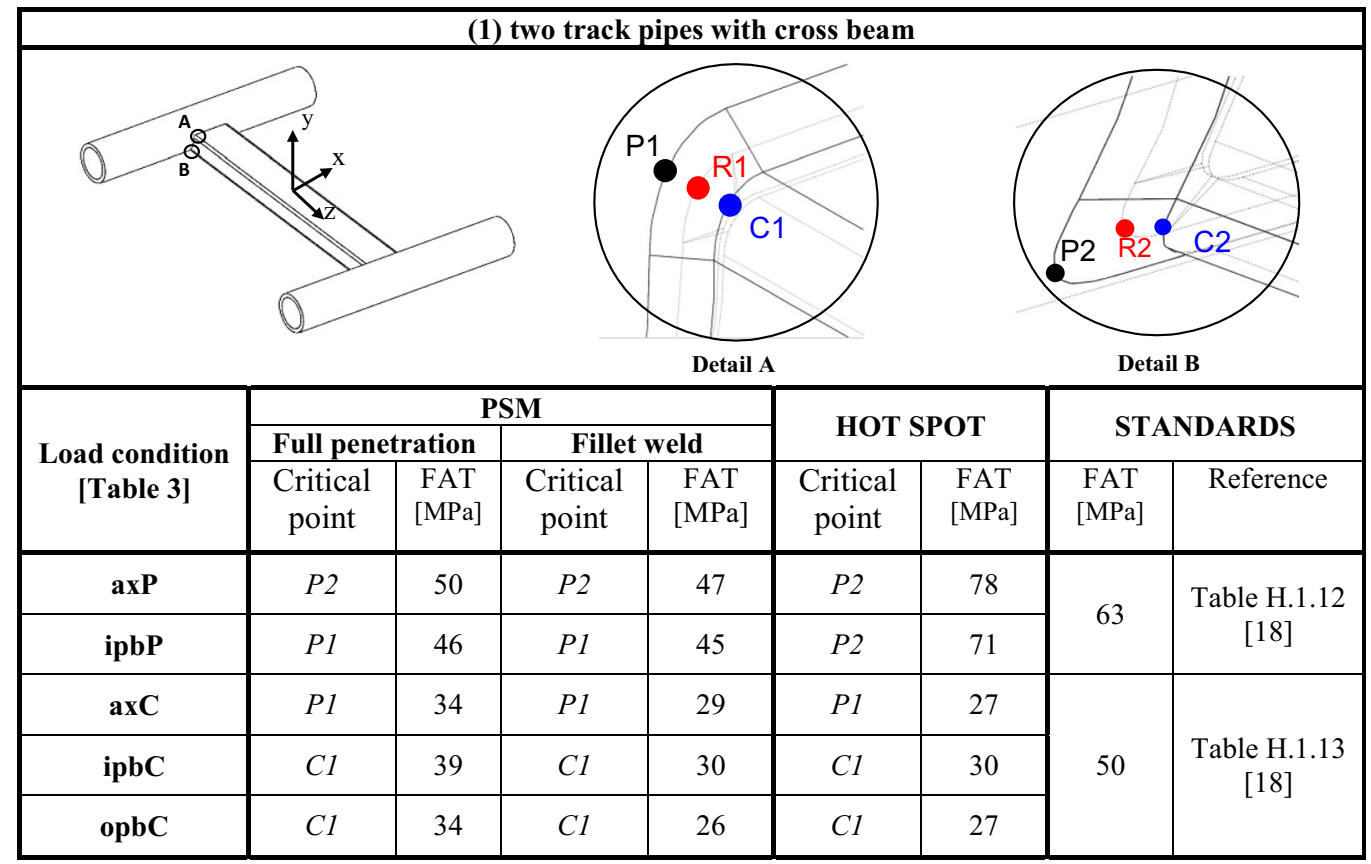

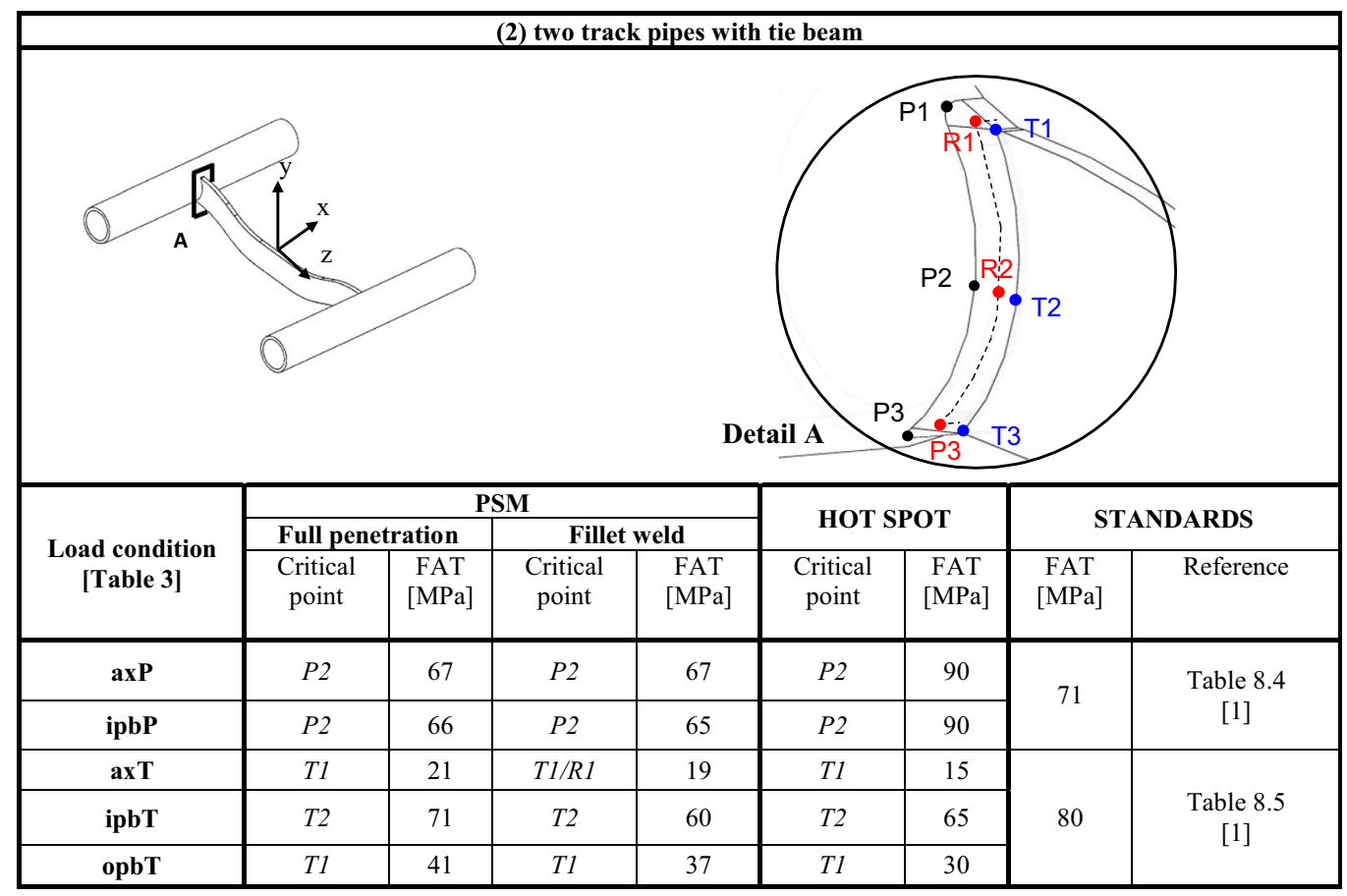




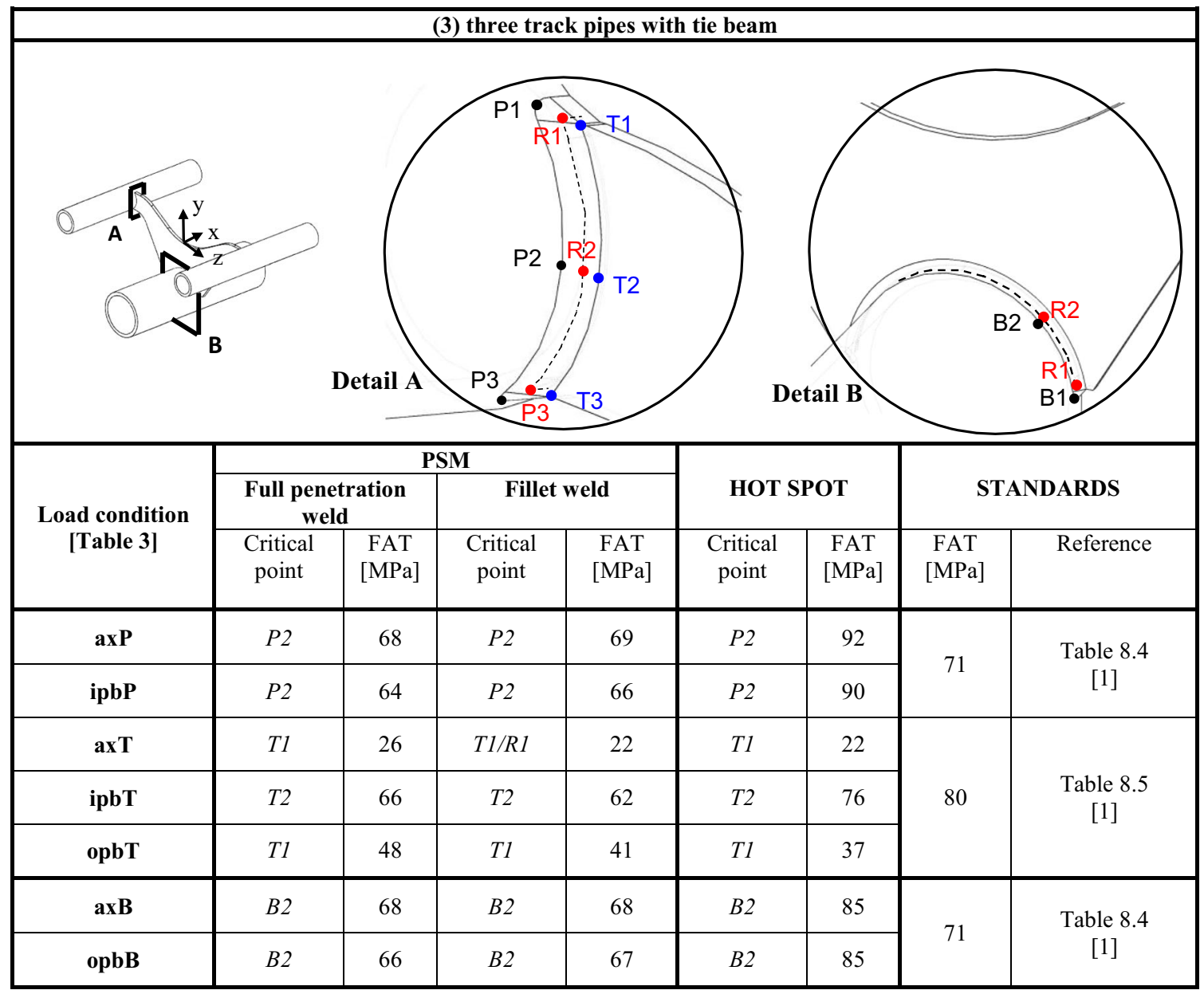

- $\Delta \sigma_{\text {nom }}$ is the nominal stress calculated in the loaded elements with thebeam theory $\frac{\mathrm{F}}{\mathrm{A}}$ for axial force and $\frac{\mathrm{M}}{\mathrm{W}}$ for bending moments, where area $(\mathrm{A})$ and section modulus $\left(W_{\mathrm{f}}\right)$ are referred to net cross-section of component (see Table 2).

- $\mathrm{FAT}_{\mathrm{HS}}$ is the FAT class at 2 million cycles and survival probability of $97.7 \%$ in terms of hot spot stress. In particular, according to [2], FAT 100 has been used for non-load carrying welds (corresponding to loads acting on track pipe, Table 3) and 90 for load-carrying welds (corresponding to loads acting on cross/tie beam, Table 3).

Table 5 reports an example of hot spot stress approach applied to the following situation:

- geometry: two track pipes with cross beam (Table 2)

- load: in plane bending of the track pipe (ipbP - Table 3)

All loading conditions shown in Table 3 have been applied to each geometry shown in Table 2 , following the procedure described in Table 5.

\section{Results}

All results obtained have been summarised in Table 6 in terms of FAT values calculated either starting from the Peak Stress Method (for full penetration and fillet weld) or starting from the hot spot stress approach.

For comparison purposes, FAT classes have been determined also from available Design Standards and in particular Eurocode 3 [1] and UNI EN 13001 [18]. However, it is worth noticing that the FAT classes available in $[1,18]$ do not faithfully reproduce the geometry of the real welded details considered in the present paper.

Table 6 reports also the position of the critical points anticipated by the PSM or the hot spot stress method. The adopted nomenclature follows the locations of the critical point: track pipe weld toe (P), backbone weld toe (B), weld root $(\mathrm{R})$, cross beam weld toe $(\mathrm{C})$ and tie beam weld toe (T); in cases of two equally critical points, both of them are indicated in Table 6 . 


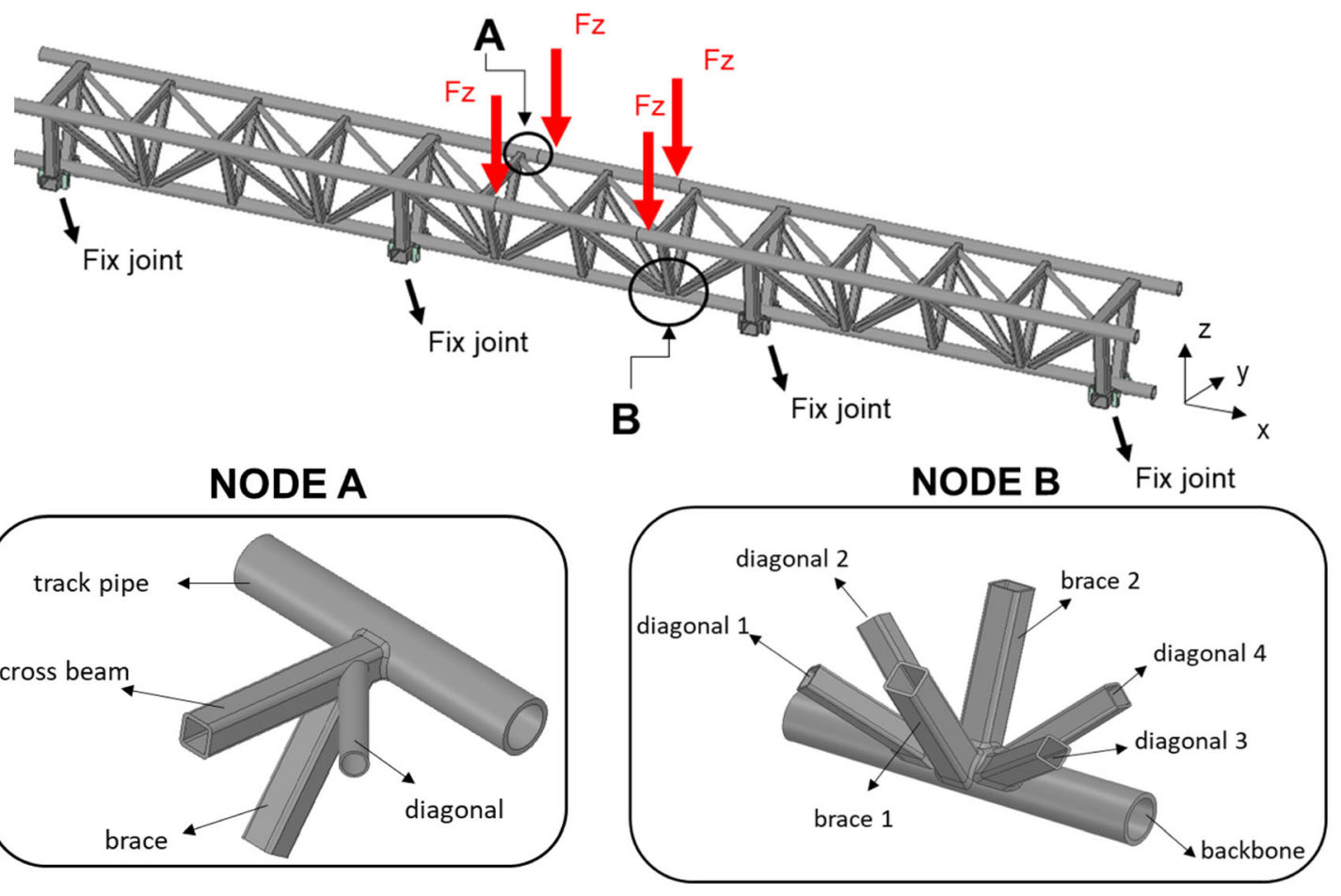

Fig. 5 Lattice structure with loads and restraint and details of nodes analysed with the PSM

It is noted that results relevant to the loading condition 'out of plane bending' of the track pipe (geometries ' 1 ', ' 2 ' and ' 3 ') and 'in plane bending' of the backbone (geometry ' 3 ') have not been reported in Table 6 because they are not considered critical for the fatigue strength.

\section{Discussion}

Some remarks that emerges from results reported in Table 6 can be stated as follows.

Table 7 Fatigue strength assessment of NODE A of lattice structure (Fig. 5)
- FAT classes taken from Design Standards are higher than those obtained from the PSM or the hot spot stress approach. This is due to the difficulty to find the appropriate geometry in the Design Standards, in particular when geometries are complex.

- FAT classes obtained from the hot spot stress method in many cases are higher than those obtained from the Peak Stress Method.

- The PSM, differently from the hot spot stress approach, allows to evaluate comparatively the fatigue criticality at the toe and at the root (for fillet or partial penetration weld).

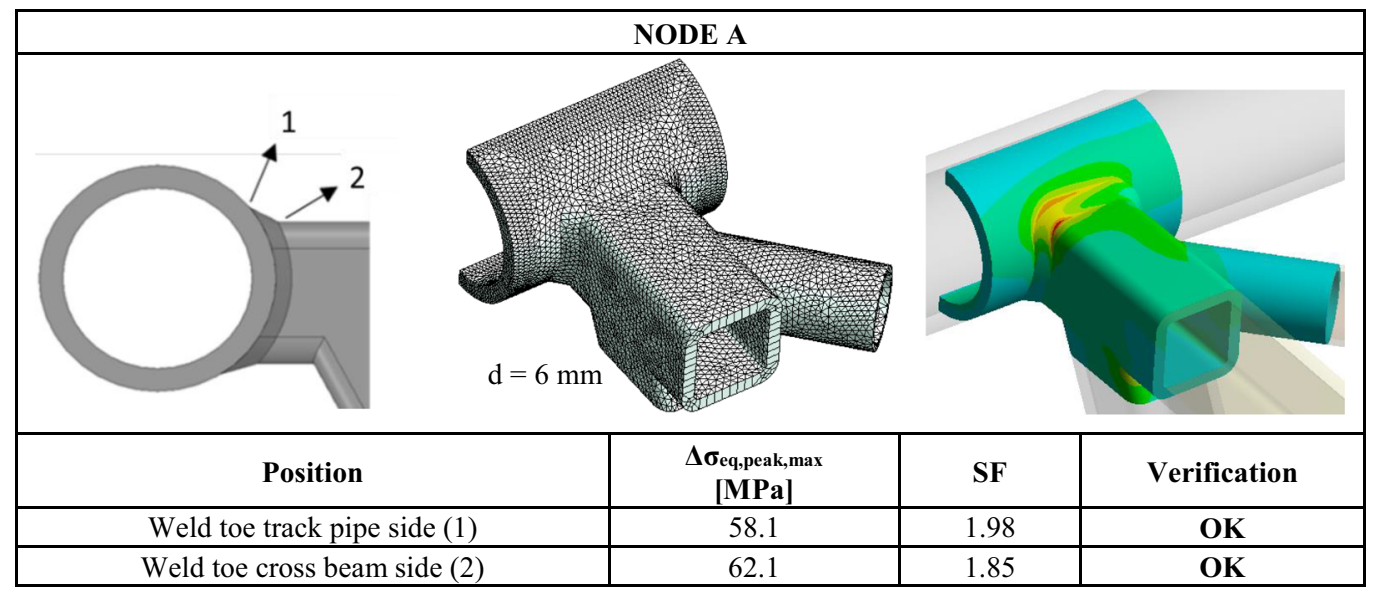


Table 8 Fatigue strength assessment of NODE B of lattice structure (Fig. 5)

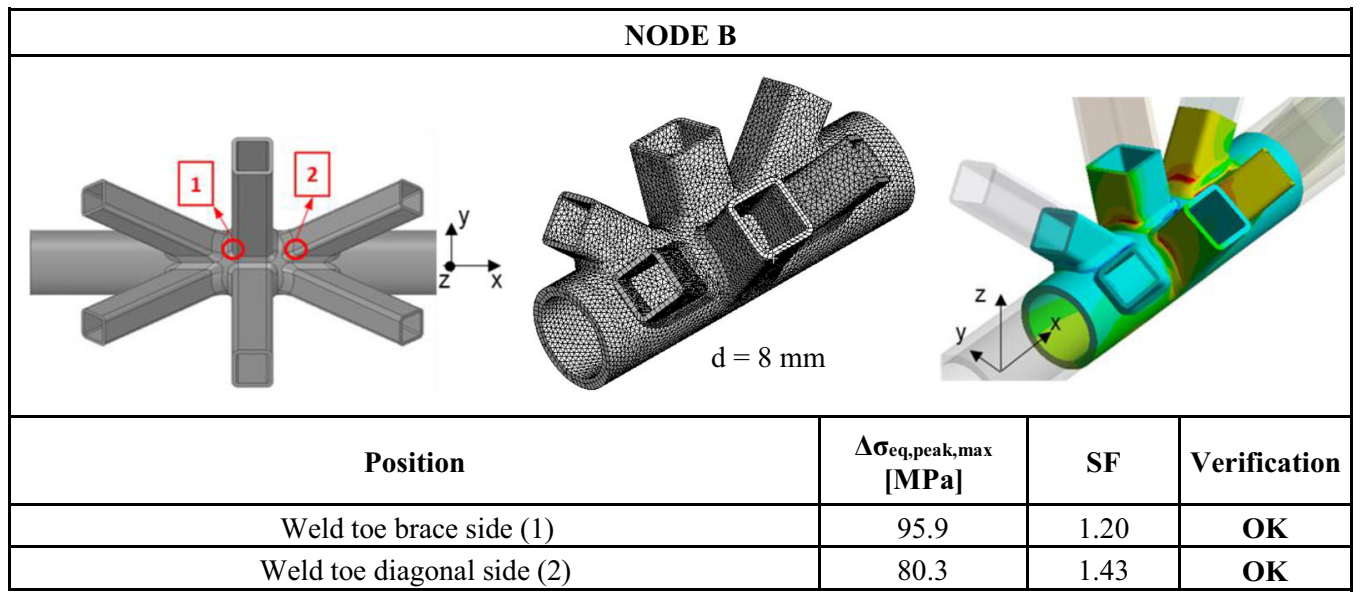

- From results obtained by adopting the PSM, it is seen that for several loading conditions (in particular for loadcarrying fillet welds: $a x C / a x T$, ipbC/ipbT, opbC/opbT), fillet welds lead to a reduction of the FAT value as compared to full penetration welds (from 15 to $25 \%$ ). It is also observed that the weld root is never the most critical point.

\section{Direct application of the PSM}

After reporting on the use of the PSM to estimate FAT classes in terms of nominal stress, a case study describing the direct application of the PSM is reported in this section, to tackle the fatigue strength assessment of two geometrically complex welded joints of a lattice-type connection (node A and node B of Fig. 5). Figure 5 reports the loading condition studied, consisting of 4 vertical forces (40 $\mathrm{kN}$ each) applied to track pipes.

\subsection{FE modelling and analysis procedure}

The procedure adopted for fatigue assessment of nodes A and B (Fig. 5) can be summarised as follows.

- 3D modelling the welded joints and meshing with 10node tetra elements in compliance with the conditions of applicability of the PSM, as reported in Table 1.

- Evaluation of the three linear elastic peak stresses $\left(\sigma_{\theta \theta, \theta=0 \text {,peak }}, \tau_{\mathrm{r} \theta, \theta=0 \text {,peak }}\right.$ and $\left.\tau_{\theta \mathrm{z}, \theta=0 \text {,peak }}\right)$, stress averaging according to Eq. (5) and stress combination (Eq. (4)) in order to obtain the average equivalent peak stress along the weld toe lines.

- The maximum value of the equivalent peak stress is used to perform the fatigue assessment by defining a safety factor $(\mathrm{SF})$ at 5 million cycles:

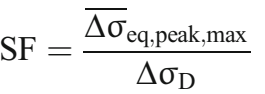

where $\Delta \sigma_{D}$ is the fatigue strength at $5 \mathrm{e} 6$ cycles valid for the design curve expressed in terms of equivalent peak stress (Fig. 2), in particular $\Delta \sigma_{D}=156 \cdot 0.737=114.9 \mathrm{MPa}$.

The fatigue assessment is satisfied if $\mathrm{SF}>1$.

\subsection{Results}

Results obtained from analysis are reported in Tables 7 and 8 for node A and node B, respectively.

For node A (Table 7), it is possible to identify two potential critical points: the weld toe on the track pipe side and the weld toe on the cross beam side. Table 7 reports the results of fatigue assessment at two critical points and also a plot of the maximum principal stress, where it is seen that the most critical position is located at the weld toe of the cross beam. Node A is verified with a SF of 1.85 .

Table 8 shows results of the fatigue strength assessment at node B. By plotting the maximum principal stress, it is seen that there are two potential critical points: the weld toe on the brace side (1) and the weld toe on the diagonal side (2). However, the average equivalent peak stress is higher at the weld toe of the brace, where the fatigue strength is assessed with a SF of 1.20

\section{Conclusions}

A method has been proposed to estimate the FAT classes in terms of nominal stress starting from the existing design curve of the Peak Stress Method (PSM). The aim is to perform FE analyses of geometrically complex welded structures by adopting beam elements, but at the same time by using FAT classes derived from a robust local approach and faithful to the 
real geometry. Welded details adopted in amusement park structures have been considered.

FAT classes can be determined also by adopting other existing approaches, for example the hot spot stress approach (as proposed in this paper) or the notch stress approach. However, the present analysis highlights the advantage of using the PSM instead of the hot spot approach in terms of the simplicity of use and time saving. This is made possible by the use of the PSM calibrated for ten-node tetrahedral elements, which allow to use relatively coarse meshes and, more important, to easily discretise complex geometries imported directly from a CAD software.

At last, a case study has been presented, where the PSM has been applied directly to assess the fatigue strength of some complex welded structures.

Acknowledgements Open Access funding provided by Università degli Studi di Padova.

Funding Open access funding provided by Università degli Studi di Padova within the CRUI-CARE Agreement.

Open Access This article is licensed under a Creative Commons Attribution 4.0 International License, which permits use, sharing, adaptation, distribution and reproduction in any medium or format, as long as you give appropriate credit to the original author(s) and the source, provide a link to the Creative Commons licence, and indicate if changes were made. The images or other third party material in this article are included in the article's Creative Commons licence, unless indicated otherwise in a credit line to the material. If material is not included in the article's Creative Commons licence and your intended use is not permitted by statutory regulation or exceeds the permitted use, you will need to obtain permission directly from the copyright holder. To view a copy of this licence, visit http://creativecommons.org/licenses/by/4.0/.

\section{References}

1. Eurocode 3 (2005) Design of steel structures - part 1-9: Fatigue. CEN.

2. Hobbacher AF (2016). Recommendations for fatigue design of welded joints and components. IIW Collection, series Editor Cècile Mayer, Second Edition. Springer International Publishing

3. Lazzarin P, Tovo R (1998) A notch intensity factor approach to the stress analysis of welds. Fatigue Fract Eng Mater Struct 21:10891103

4. Lazzarin P, Livieri P (2001) Notch stress intensity factors and fatigue strength of aluminium and steel welded joints. Int J Fatigue $23: 225-232$
5. Meneghetti G, Lazzarin P (2007) Significance of the elastic peak stress evaluated by FE analyses at the point of singularity of sharp V-notched components. Fatigue Fract Eng Mater Struct 30:95-106

6. Meneghetti G (2012) The use of peak stress method for fatigue strength assessments of welded lap joints and cover plates with toe and root failures. Eng Fract Mech 89:40-51

7. Meneghetti G (2013) The peak stress method for fatigue strength assessment of tube-to-flange welded joints under torsion loading. Weld World 57:265-275

8. Meneghetti G, Guzzella C (2014) The peak stress method to estimate the mode I notch stress intensity factor in welded joints using three-dimensional finite element models. Eng Fract Mech 115:154171

9. Meneghetti G, Campagnolo A, Avalle M, Castagnetti D, Colussi M, Corigliano P et al (2017) Rapid evaluation of notch stress intensity factor using the peak stress method: comparison of commercial finite element codes for a range of mesh patterns. Fatigue Fract. Eng. Mater. Struct. 41:967-1242

10. Lazzarin P, Zambardi R (2001) A finite-volume-energy based approach to predict the static and fatigue behavior of components with sharp V-shaped notches. Int J Fract 112:275-298

11. Lazzarin P, Livieri P, Berto F, Zappalorto M (2008) Local strain energy density and fatigue strength of welded joints under uniaxial and multiaxial loading. Eng Fract Mech 75:1875-1889

12. Lazzarin P, Sonsino CM, Zambardi R (2004) A notch stress intensity approach to assess the multiaxial fatigue strength of welded tube-to-flange joints subjected to combined loadings. Fatigue Fract Eng Mater Struct 27:127-140

13. Lazzarin P, Lassen T, Livieri P (2003) A notch stress intensity approach applied to fatigue life predictions ofwelded joints with different local toe geometry. Fatigue Fract Eng Mater Struct 26: $49-58$

14. Livieri P, Lazzarin P (2005) Fatigue strength of steel and aluminium welded joints based on generalised stress intensity factors and local strain energy values. Int J Fract 133:247-276

15. Meneghetti G, Campagnolo A, Rigon D (2017) Multiaxial fatigue strength assessment of welded joints using the Peak Stress Method - part I: approach and application to aluminium joints. Int J Fatigue 101:328-342

16. Meneghetti G, Campagnolo A, Rigon D (2017) Multiaxial fatigue strength assessment of welded joints using the Peak Stress Method - part II: application to structural steel joints. Int J Fatigue 101:343362

17. Meneghetti G, Campagnolo A (2018) Rapid estimation of notch stress intensity factors in 3D large-scale welded structures using the peak stress method. MATEC Web of Conferences 165:17004. https://doi.org/10.1051/matecconf/201816517004

18. UNI EN 13001-3-1. Cranes - general design - part 3-1: limit states and proof competence of steel structure.

Publisher's note Springer Nature remains neutral with regard to jurisdictional claims in published maps and institutional affiliations. 